\title{
Study of Al-SiO2 aesthetic composite coating on the orthodontic metal arch wire
}

\section{Jie Yang}

School and Hospital of Stomatology, China Medical University, Liaoning Provincial Key Laboratory of Oral Diseases, Shenyang 110002, China

\section{Bowen Zheng}

School and Hospital of Stomatology, China Medical University, Liaoning Provincial Key Laboratory of Oral Diseases, Shenyang 110002, China

\section{Yuwen Yan}

School and Hospital of Stomatology, China Medical University, Liaoning Provincial Key Laboratory of Oral Diseases, Shenyang 110002, China

\section{Haopeng Wu}

School and Hospital of Stomatology, China Medical University, Liaoning Provincial Key Laboratory of Oral Diseases, Shenyang 110002, China

\section{Fan Liu}

School and Hospital of Stomatology, China Medical University, Liaoning Provincial Key Laboratory of Oral Diseases, Shenyang 110002, China

\section{Dake Xu}

Shenyang National Laboratory for Materials Science, Northeastern University, Shenyang 110819, China Yi Liu ( $\square$ liuyi@cmu.edu.cn )

School of Stomatology, China Medical University https://orcid.org/0000-0002-4640-3396

\section{Nano Express}

Keywords: aluminum-silicon dioxide, surface modi cation, corrosion

Posted Date: December 15th, 2020

DOl: https://doi.org/10.21203/rs.3.rs-126592/v1

License: (c) (i) This work is licensed under a Creative Commons Attribution 4.0 International License. Read Full License 


\title{
RESEARCH
}

\section{Study of $\mathrm{Al}-\mathrm{SiO}_{2}$ aesthetic composite coating on the orthodontic metal arch wire}

\author{
Jie Yang ${ }^{1}$, Bowen Zheng ${ }^{1}$, Yuwen Yan ${ }^{1}$, Haopeng $\mathrm{Wu}^{1}$, Fan $\mathrm{Liu}^{1}$, Dake $\mathrm{Xu}^{2}$ and $\mathrm{Yi} \mathrm{Liu}^{3 *}$
}

\author{
${ }^{*}$ Correspondence: \\ liuyi@cmu.edu.cn \\ ${ }^{1}$ School and Hospital of \\ Stomatology, China Medical \\ University, Shenyang, China \\ Full list of author information is \\ available at the end of the article
}

\begin{abstract}
Nickel-titanium orthodontic wires (NTWs) play enssential roles in orthodontic treatment. However, the corrosion and unaesthetic characteristics limit their applications. To increase to aesthetic effects of nickel-titanium orthodontic wires, we prepared aluminum-silicon dioxide $\left(\mathrm{Al}-\mathrm{SiO}_{2}\right)$ as biocompatible layer coated onto nickel-titanium orthodontic wires. $\mathrm{Al}-\mathrm{SiO}_{2}$ coating were firstly fabricated by using physical vapor deposition magnetron sputtering. Physicochemical properties and biocompatibility were investigated. $\mathrm{Al}-\mathrm{SiO}_{2}$ layer were well coated onto NTWs. A reduced corrosion current density and friction coefficient were observed in $\mathrm{Al}-\mathrm{SiO}_{2}$ coated NTWs. Additionally, favorable biocompatibility was found in $\mathrm{Al}-\mathrm{SiO}_{2}$ coated NTWs, indicating $\mathrm{Al}-\mathrm{SiO}_{2}$, prepared as novel aesthetic layer, could enhance NTWs Physicochemical properties without cytotoxicity, and had great potential for NTWs surface modification.
\end{abstract}

Keywords: aluminum-silicon dioxide; surface modification; corrosion

\section{Introduction}

Brackets and archwires are two major parts in fixed appliance technologies. In detail,backets could align the teeth under continuous forces imposed by archwires. Although several aesthetic appliances have been applied for orthodontic treatment, stainless steel brackets and nickel-titanium wires (NTWs) are still mostly used in clinical treatment. To our knowledge, metal materials can naturally corrode when exposed to air or water[1], let alone oral cavity, which is an extremely complex environment, and easily affected by saliva, bacterial flora, food, temperature fluctuations and mechanical forces. Corrosion can increase the surface roughness of the metal surface, resulting in an increased friction forces between the archwire and the bracket, and sequentially hinder teeth movement. Additionally, the increased friction would accelerate the corrosion process under continuously increasing stress $[2,3]$. To overcome the corrosion and unaesthetic characteristics of metal materials, aesthetic layers including rhodium, epoxy resin, polytetrafluoroethylene, platinum silver have been applied to improve metal physicochemical properties. However, some drawbacks (i.e. color instability, biocompatibility and lack of bonding strength) still need to be carefully addressed.[4, 5, 6, 7]. Thus, the development of archwires with stable coating properties and certain resistance to corrosion or friction is an increasing of interests for orthodontic treatment. Aluminum ( $\mathrm{Al})$, the most abundant metal element in earth, has been widely used as biomedical materials. Silicon dioxide $\left(\mathrm{SiO}_{2}\right)$ is commonly used as modification layer due to its 
superior physicochemical stability and favorable biocompatibility. Importantly, Oxide layer could impede ion movement as well as release to improve metal mechanical properties and stability. physical vapor deposition magnetron sputtering (PVDMS) is widely used to prepare coating layers and the color of the alumina film produced by PVDMS is transparent. additionally, magnetron sputtering has strong bonding force between coating and substrate as well as satisfactory uniformity of metal surface. The high deposition rate and high-purity thin film are easily formed on many metals and alloys by using PVDMS technology. [8, 9, 10, 11]. In consideration of the advantages of aluminum and silicon dioxide, we prepared novel modified layer based on $\mathrm{Al}-\mathrm{SiO}_{2}$ composite and explored its potential application in fixed application. In detail, $\mathrm{Al}-\mathrm{SiO}_{2}$ were firstly fabricated (PVDMS). Physicochemical properties were evaluated by scanning electron microscope (SEM), energy dispersive spectrometer (EDS), electrochemical corrosion and friction analysis. Mouse broblasts cells were used to investigate the biocompatibility of $\mathrm{Al}-\mathrm{SiO}_{2}$ coated samples

\section{Materials and methods}

Preparation and characterization of $\mathrm{Al}-\mathrm{SiO}_{2}$ coated samples

Commercial orthodontic stainless steel archwires (SSA) and NiTi archwires (NTA) were selected as substrates (Shanghai Emundi, $0.016 \times 0.022$ inch). Besides, $2 \times 2$ $\times 0.2 \mathrm{~cm} 3 \mathrm{SS}$ and NT samples were prepared for further research. The distance of tatget materials and specimen stage was set to $7 \mathrm{~cm}$. The argon gas could be passed into the vacuum chamber, when the vacuum was lower than $3 \times 10-3 \mathrm{~Pa}$,sequentially initiated the process of pre-sputtering of the target with following parameters: Pressure: $0.5 \mathrm{~Pa}$; Pre-sputtering time: $15 \mathrm{~min}$. Al deposition time:10 min $\mathrm{SiO}_{2}$ deposition time: $150 \mathrm{~min}$. Pulse voltage: $350 \mathrm{~V}$, the duty cycle: $15 \%$, Substrate voltage: 340V; Deposition temperature: $250{ }^{\circ} \mathrm{C}$. The microstructure and sueface morphology of specimens were characterized by scanning electron microscopy (SEM) after gold spraying under the vacuum pressure for $90 \mathrm{~s}$. Additionally,the elemental composition of the coated layer was analyzed by using energy dispersive spectroscopy EDS.

\section{Cytotoxicity Tests}

Cells were cultured at a density of $2 \times 104$ per sample for 1, 3, 5, and 7 days. Cell viability was evaluated using Cell Counting Kit-8 (CCK-8, Beyotime, Shanghai, China). At each time point, the samples were washed twice with PBS. Fresh culture medium $(200 \mu L)$ was mixed with $20 \mu L$ of CCK-8 reagent and added to each sample. Then, the culture was incubated at $37^{\circ} \mathrm{Cfor} 2 \mathrm{~h}$. After the incubation, 100 $\mu L$ of the medium was transferred to a 96 -well plate and measured at $450 \mathrm{~nm}$.

\section{Electrochemical corrosion experiments}

The electrochemical workstation CHI760D (Reference 600, Gamry company, USA) was used to investigate the electrochemical performance of the coated layer. A conventional three-electrode set up was used for electrochemical measurement, with $\mathrm{Pt}$ as a counter electrode, standard $\mathrm{Ag} / \mathrm{AgCl}$ as a control, and the anodized specimen as the working electrode. Electrochemical tests were performed on the specimens in artificial saliva. The uncoated surface was closed with nail polish at room temperature. T. The dynamic polarization curve measurements were then conducted when 
the OCP was stable. The scanning speed was $0.33 \mathrm{mV} / \mathrm{s}$, and the scanning range was from $-0.1 \mathrm{~V}$ to $1.5 \mathrm{~V}$.

\section{Wear test}

Rotary friction and wear machine (Lanzhou Institute of Chemical Physics, Chinese Academy of Sciences) to investigate the friction and wear performance of the coated layers. The friction pair used was an Al2O3 ball with a diameter of $4 \mathrm{~mm}$, the rotation speed was $200 \mathrm{r} / \mathrm{min}$, and the applied load was $1 \mathrm{~N}$. The test was performed in a room temperature atmosphere. The friction and wear of the coating were generally divided into three phases, namely the running-in phase, the stable phase, and the failure phase. Then, the average value of the friction coefficient in the stable phase as the friction coefficient of the coating was recorded.

\section{Scratch test}

The bonding strength of the coated layers was tested by using MFT-4000 scratch tester (Lanzhou Institute of Chemical Physics, Chinese Academy of Sciences). Test parameters were depicted as follow: radius: $0.2 \pm 0.01 \mathrm{~mm}$; scratch length: $5 \mathrm{~mm}$; loading speed: $30 \mathrm{~N} / \mathrm{min}$; end load: $70 \mathrm{~N}$.

\section{Statistical analysis}

Statistical analysis was performed using SPSS 21.0 software. All data are depicted as mean \pm standard deviation values. One-way analysis of variance (ANOVA) was first used to evaluate the statistical significance among five groups. Paired t test was used to evaluate the differences between each of the two groups. A p value of less than 0.05 was considered as statistically significant.

\section{Results}

Results

The cross-section and surface morphologies of the coated layers were shown in Figure 1. As showed in Figure 1a, the thickness of coated layers was 1.8. Especially, all samples displayed uniform and dense layers that securely attached to the substrate, without any interfacial defects.

\section{EDS analysis}

The EDS results of the coated layer displayed the presence of the aluminum and silicon peaks in samples, which demonstrated the $\mathrm{Al}-\mathrm{SiO}_{2}$ layers were well coated on sampes

cytotoxicity

Figure 3 and figure 4 show OD values and cytotoxicity levels of archwires at different time intervals $(1,3,5$, and 7$)$ days. The statistical results found that there was no significant difference in the experimental group, control group, and blank group. The OD values of the experimental group, the control group, and the blank group increased with the increase of the culture time, which indicated that the cells grew well and preserved their proliferation ability. According to the cytotoxicity assessment, the cytotoxicity of the coated archwire in the experimental group was within the safe range. 


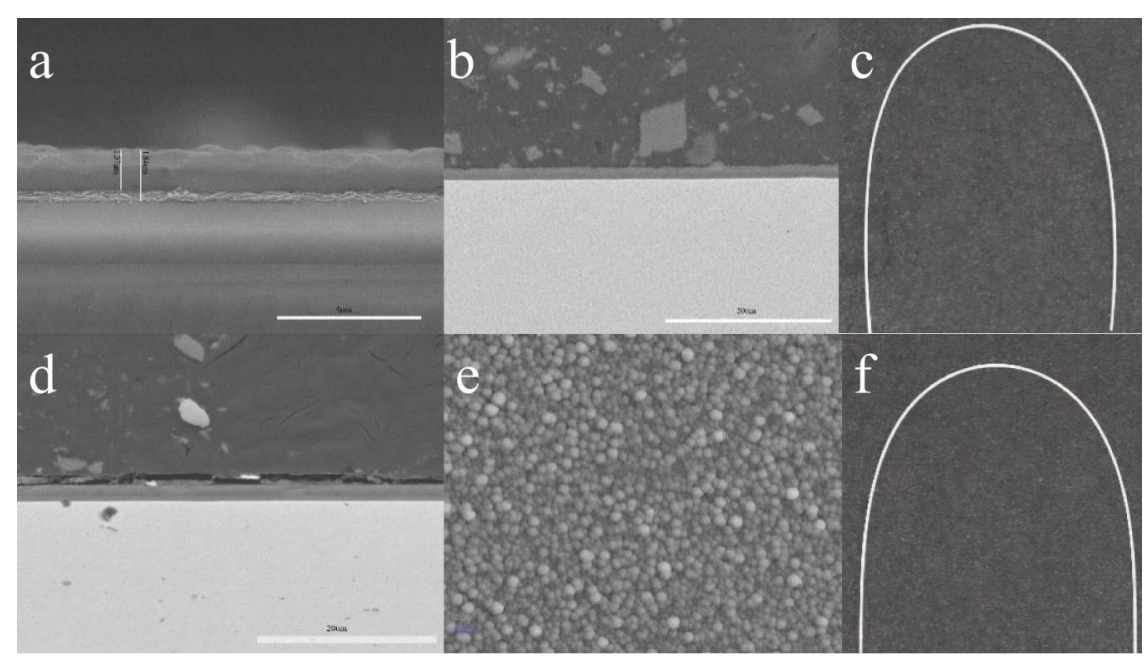

Figure $1 \mathrm{SEM}$ observation and archwire morphology of $\mathrm{Al}-\mathrm{SiO}_{2}$ coated layer.(a: coating thickness; b: stainless steel section; c: nickel-titanium section; d: coating surface; e: the morphology of $\mathrm{NiTi}$ archwire; f: the morphology of stainless steel archwire)

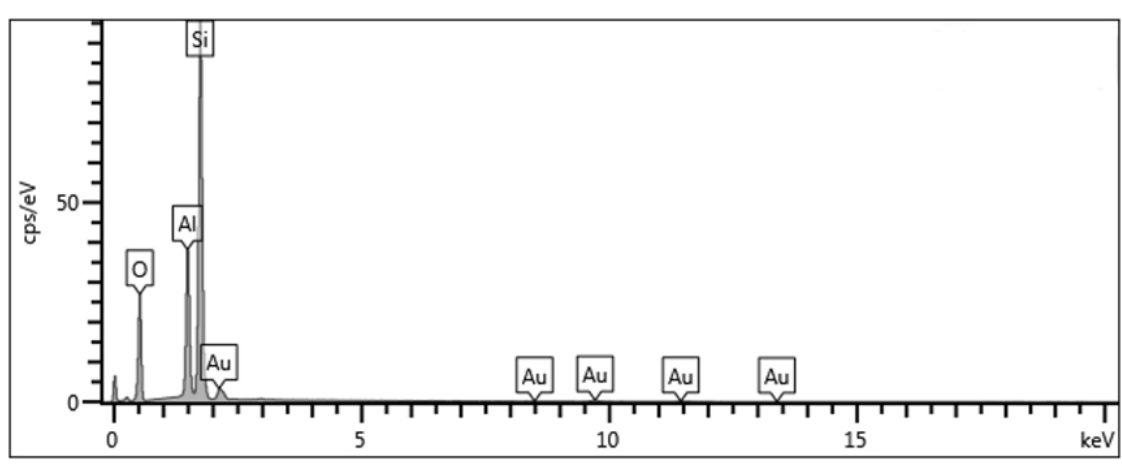

Figure 2 EDS pattern of $\mathrm{Al}-\mathrm{SiO}_{2}$ coating

\section{Electrochemical corrosion experiments}

Electrochemical results were shown in Figure 5 and Figure 6. The corrosion current of the NiTi control group, the NiTi experimental group, the stainless steel control group, and the stainless steel experimental group were $23.72 \mathrm{uA} / \mathrm{cm} 2,1.21 \mathrm{uA}$ $/ \mathrm{cm} 2,0.22 \mathrm{uA} / \mathrm{cm} 2,0.06 \mathrm{uA} / \mathrm{cm} 2$, respectively. The polarization currents in experimental groups decreased in comparision to the control groups. The polarization current shows that the preparation of $\mathrm{Al}-\mathrm{SiO}_{2}$ coating on the surface of $\mathrm{NiTi}$ and stainless steel could reduce the tendency of electrochemical corrosion. Therefore, the present results demonstrate that $\mathrm{Al}-\mathrm{SiO}_{2}$ coating improves the corrosion resistance of the archwires.

\section{Friction and wear properties}

The test conditions are shown in Table 1. Figure 7 and Figure 8 showed the curve of the friction coefficient of the coated layers. The friction process could be divided into two phases: The friction coefficient changed over time in phase I, which is in unstable 


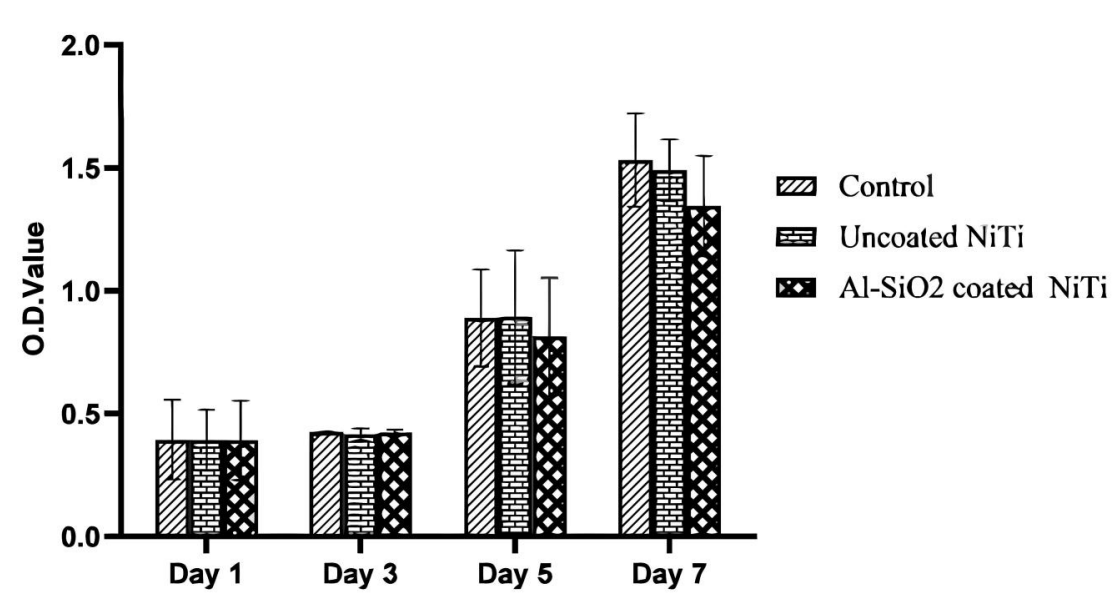

Figure 3 Optical density (OD) values at different time points in the NiTi group

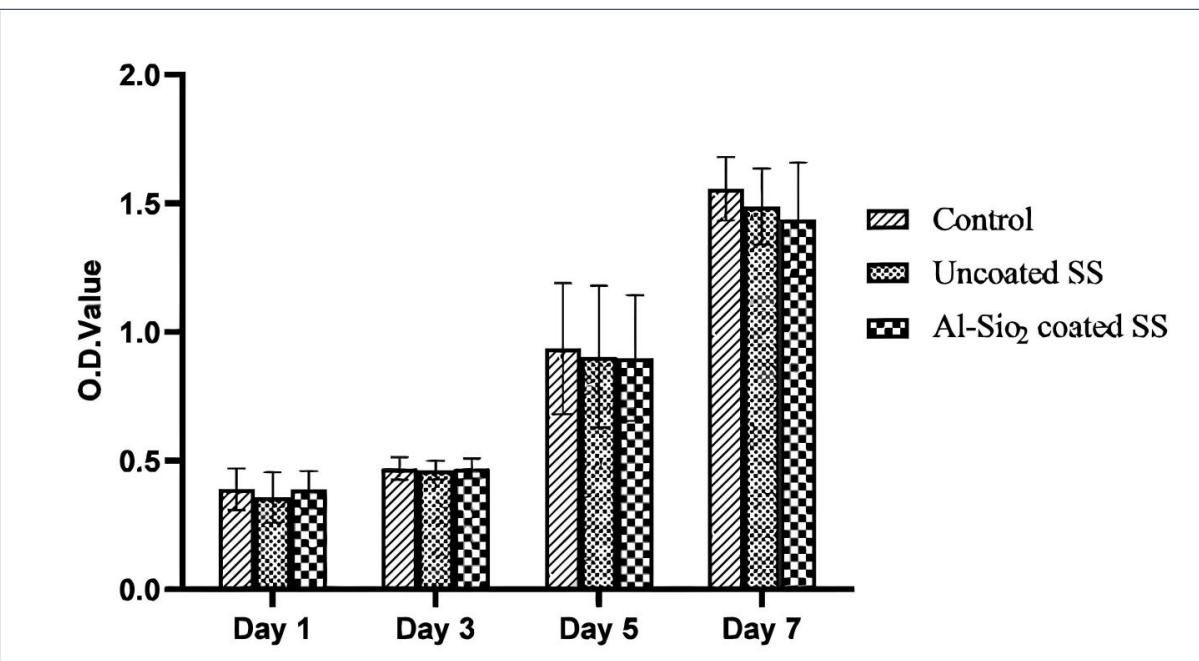

Figure 4 Optical density (OD) values of mouse fibroblasts at different time points in the stainless steel group

running-in phase. In phase II, the friction coefficient tends to be stable. The mean value of the friction coefficient in the stable phase as the friction coefficient of the coating was recorded. The friction coefficients of the NiTi control and experimental groups, the SS control and experimental groups, were $0.68,0.46,0.58$, and 0.45 , respectively.

Table 1 The process parameters of wear test

\begin{tabular}{ccccc}
\hline friction pairs & load $(\mathrm{N})$ & Turning radius $(\mathrm{mm})$ & Speed $(\mathrm{r} / \mathrm{min})$ & test time $(\mathrm{min})$ \\
\hline alumina ball $(\phi=4 \mathrm{~mm})$ & 1 & 3 & 200 & 30 \\
\hline
\end{tabular}

Bonding strength

Figure 9 and Figure 10 showed the critical load (Lc) which is at a sharp peak of the curve. The position of the inflection point coincided with the location of the 


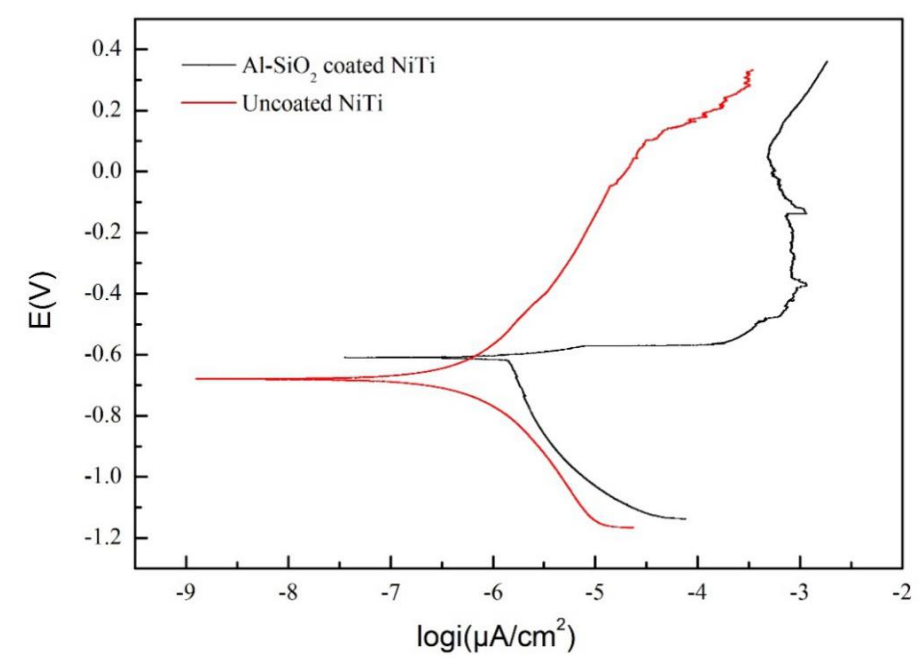

Figure 5 Dynamic polarization curve of $\mathrm{NiTi}$ group

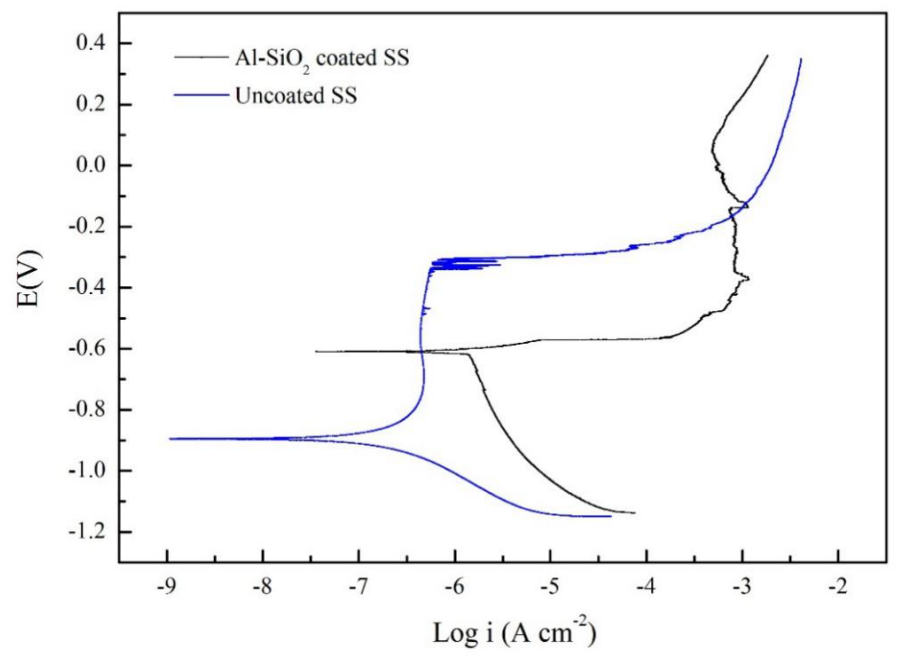

Figure 6 Dynamic polarization curve of stainless steel group

first acoustic signal, corresponding to the critical load. The mean Lc value of the $\mathrm{Al}-\mathrm{SiO}_{2}$ coated NiTi archwires, and stainless steel archwires were $15.07 \mathrm{~N}$ and $8.3 \mathrm{~N}$, respectively. High vacuum plasma ion titanium sputtering was carried out on NiTi archwires with a titanium disc (i.99.9\%) as the sputtering target materials according to the experiment by Anuradha $\mathrm{P}[12]$, and the coatings were found to be relatively stable on a linear scratch test when Lc was greater than $8 \mathrm{~N}$, therefore; $8 \mathrm{~N}$ was used as a control group to evaluate the binding force of the $\mathrm{Al}-\mathrm{SiO}_{2}$ 


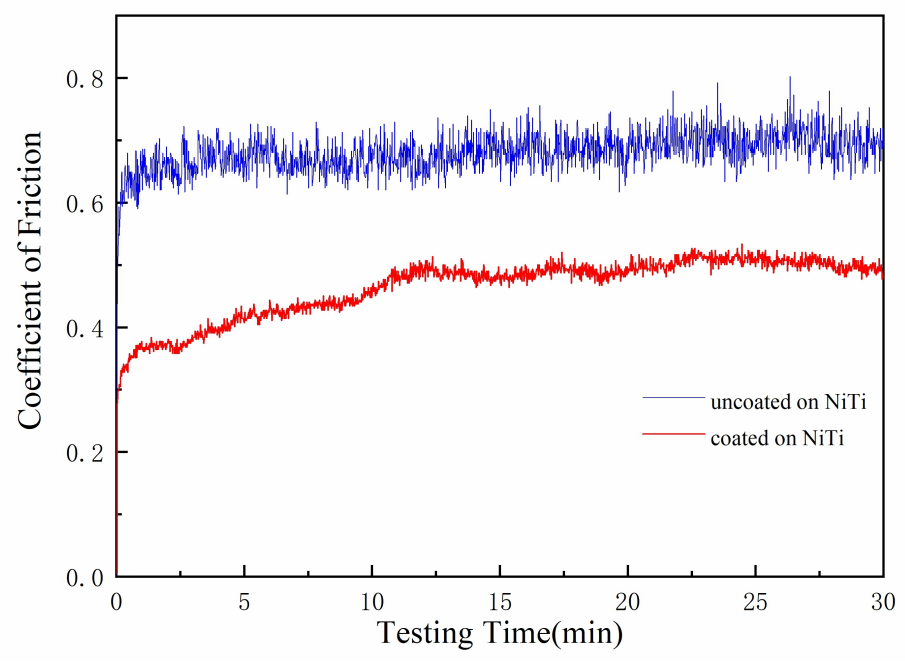

Figure 7 Friction coefficient curve of NiTi group

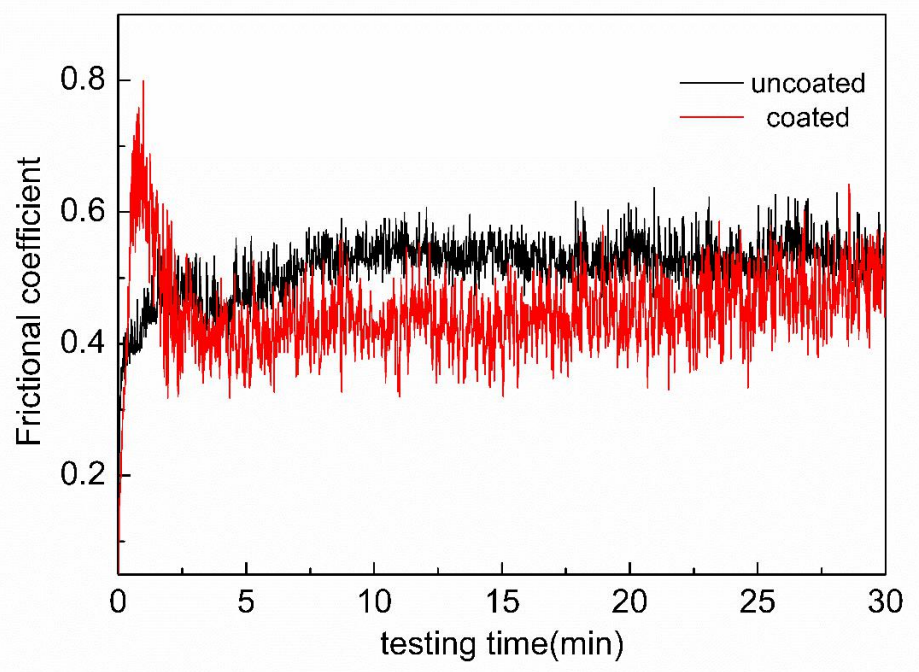

Figure 8 Friction coefficient curve of stainless steel group

coating. The $\mathrm{Al}-\mathrm{SiO}_{2}$ coatings were found to be relatively stable on the linear scratch test and could meet the requirement of the clinic.

\section{Discussion}

As the development of esthetic dental appliances, the orthodontic archwires must meet certain requirements prior they could be used clinically including high strength, low friction, corrosion resistance, friction resistance, and biocompatibility [13]. Various coatings have been developed to modify the surface of orthodontic arch- 


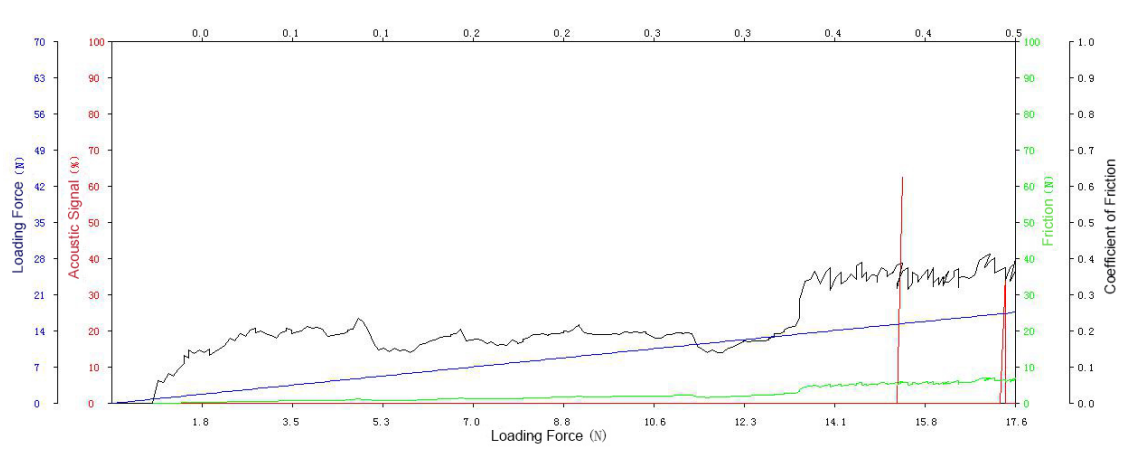

Figure 9 The scratch test shows coated NiTi specimen.

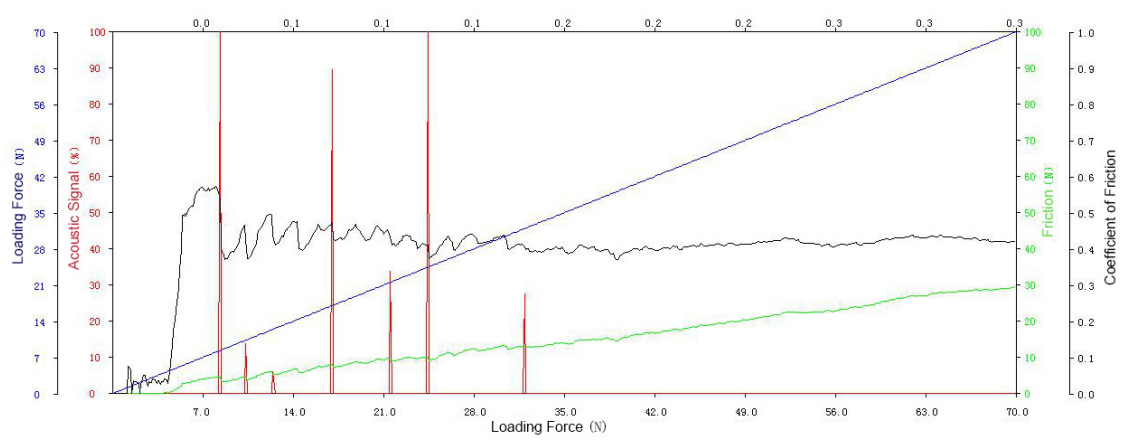

Figure 10 The scratch test shows coated stainless steel specimen.

wires to improve their physicochemical and biological properties.. In present study, $\mathrm{Al}-\mathrm{SiO}_{2}$ coated layers have been prepared as esthetic orthodontic archwires with satisfactory biocompatibility and physical properties. The results of CCK8 (Cell Counting Kit-8)and the level of cytotoxicity at different time inervals $(1,3,5$, and 7 days) of the archwires evaluated are shown in figure 3 and 4 . No signicant differences in cytotoxicity were found between the $\mathrm{Al}-\mathrm{SiO}_{2}$ samples and the control group. Therefore, $\mathrm{Al}-\mathrm{SiO}_{2}$ coated layers could be considered as a safe and useful method for clinical application. Various substances in the mouth can cause electrochemical corrosion reactions on the surface of the archwires [14]. The presence of different metallic elements in the oral cavity may lead to the formation of electro-galvanic cells which may induce corrosion. Microorganisms such as sulfate-reducing bacteria may also be present among the metabolic microflora in the oral cavity, which can induce biological corrosion. Microorganisms can change the conditions on the surface of biomaterials and contribute to the intensification of the biocorrosion processes [15]. The biofilm formation leads to the change of oral cavity parameters, such as PH, electrolytic concentration, or oxygen levels. Further, there are three types of corrosive cells in the oral environment; cells with varying degrees of oxygenation, cells containing different concentrations of metal ions, and active-passive cells $[15,16,17]$. The corrosion resistance of aesthetic archwires in clinical still needs to be improved at present. It is found that rhodium coating is esthetically pleasing but with the low corrosion resistance, which may be due to the galvanic 
coupling between the noble coating and the base alloy [18]. Previous literature have investigated polymer coatings such as epoxy resins which reduced the corrosion resistance of archwires compared to uncoated NiTi and stainless steel archwires[19]. It is required to produce orthodontic archwires with certain corrosion resistance. The present outcomes demonstrated that $\mathrm{Al}-\mathrm{SiO}_{2}$ coatings could decrease the corrosion rates of $\mathrm{NiTi}$ and stainless steel archwires in artificial saliva through polarization curves, which achieved from corrosion tests. The microstructures and compositions of the $\mathrm{Al}-\mathrm{SiO}_{2}$ coatings with a smooth surface is uniform and could provide better protection for the surface of the archwires. To our knowledge, the existence of friction could affect the teeth movement efficiency during fixed orthodontic treatment. Kusy et al. demonstrated that $12-60 \%$ of the orthodontic force might be reduced by friction throughout orthodontic treatment and inevitably affected the clinical treatment [20]. Previous researches have verified that certain aesthetic coated archwires could increase the roughness. Studies have investigated microscopic observations on uncoated archwires and rhodium-coated aesthetic archwires, the results showed that rhodium archwires increase the roughness of NiTi archwires [21, 12]. Another study found that the surface roughness of rhodium-coated archwires presented similar to that of uncoated archwires. However, Teflon and epoxy coated archwires showed a significant difference in surface roughness compared to uncoated archwires, the surface roughness of Epoxy coating is higher than the Teflon [4]. Woowa aesthetic archwire has a compound double-layered coating structure with a silver and platinum coating inside, and a special polymer coating outside. The latter can provide aesthetic requirements; however, the surface roughness of the coating is not acceptable. The results of the wear test in present study displayed that the friction coefficients of $\mathrm{Al}-\mathrm{SiO}_{2}$ coated SS and NT archwires were lower than those of uncoated groups. Therefore, the $\mathrm{Al}-\mathrm{SiO}_{2}$ coated layers formed by magnetron sputtering improve the friction resistance of orthodontic archwires. The thickness of the coating is an essential factor, which is closely related to the expression of torque. The thickness of the coating achieved by the PVD is thinner than that by electroplating and electroless plating [22, 23, 24]. Anuradha $\mathrm{P}[23]$ et al. reported a uniform, dense titanium coating layer, which was observed by magnetron sputtering, where the thickness varied from $3-5 \mu \mathrm{m}$. Woowa [22] aesthetic archwire has a compound double-layered coating structure with a silver and platinum coating inside and a special polymer coating outside where the thickness is $10 \mu \mathrm{m}$. Alavi and Hosseini [24] et al. found that the thickness of the epoxy resin coating on G H1 Wire was approximately $0.05 \mathrm{~mm}$ through experiments. These archwires have been used in clinical. The thickness of the $\mathrm{Al}-\mathrm{SiO}_{2}$ coating in this experiment is about $1.8 \mathrm{um}$, which is far lower than the thickness of the current clinical aesthetic coatings. Therefore, the $\mathrm{Al}-\mathrm{SiO}_{2}$ coating has little impact on the size of the archwire and the $\mathrm{Al}-\mathrm{SiO}_{2}$ coating prepared by magnetron sputtering can be used on the surface of orthodontic archwires. $\mathrm{Al}-\mathrm{SiO}_{2}$ coated archwires have various advantages, including aesthetics, corrosion resistance, bonding strength, and biological safety when compared with uncoated archwires. The $\mathrm{Al}-\mathrm{SiO}_{2}$ coating can not only meet the mechanical properties which are necessary for orthodontics but also match the aesthetics that metal archwires cannot achieve. the newly formed $\mathrm{Al}-\mathrm{SiO}_{2}$ coated layers displayed a color difference that was almost identical to 
the coated wires that are used commercial used in clinic. However, the color of the $\mathrm{Al}-\mathrm{SiO}_{2}$ coated layer needs to be further optimized and verified through fading experiments to better approximate the natural color of the teeth. The presence of saliva, plaque and corrosion in the oral cavity may affect the performance of the archwire since this study was conducted under ideal laboratory conditions [25]. To simulate orthodontic tooth movement in the clinical aspect, further research is needed to evaluate specifically in different situations, which focus on the optimization of $\mathrm{Al}-\mathrm{SiO}_{2}$ coated archwire, and further improve its technological parameter and manufacture technology to increase the bonding force of the coating.

\section{Conclusion}

In present study, $\mathrm{Al}-\mathrm{SiO}_{2}$ coating was well prepared on the surface of nickeltitanium and stainless steel archwires by magnetron sputtering, and it confirmed biological safety and improved physical properties.

\section{Acknowledgements}

The authors would like to express their thanks to teachers and students in the Experimental Centre of School and Hospital of Stomatology, China Medical University, for their continuous help and support.

\section{Funding}

This work was financially supported by Youth backbone support program of China medical universityQGZ2018070Liaoning province key research and development guidance plan project (Grant No. 2020JH2/10300038) and Shenyang Science and Technology Project (20-205-4-099).

Competing interests

The author(s) declared no potential conflicts of interest with respect to the research, authorship, and/or publication of this article.

\section{Author details}

${ }^{1}$ School and Hospital of Stomatology, China Medical University, Shenyang, China. ${ }^{2}$ Shenyang National Laboratory for Materials Science, Northeastern University, Shenyang, China. ${ }^{3}$ Department of Orthodontics, School of Stomatology, China Medical University, Shenyang, China.

\section{References}

1. Dias, V., Maciel, H., Fraga, M., Lobo, A.O., Pessoa, R.: Atomic layer deposited tio2 and al2o3 thin films as coatings for aluminum food packaging application. Materials 12(4), 682 (2019)

2. Nik, T.H., Hooshmand..., T.: Effect of chlorhexidine-containing prophylactic agent on the surface characterization and frictional resistance between orthodontic brackets and archwires: an in vitro study. Progress in Orthodontics 14(1), 48-48 (2013)

3. Hafez, H.S., Selim, E.M.N., Eid, F.H.K., Tawfik, W.A., Al-Ashkar, E.A., Mostafa, Y.A.: Cytotoxicity, genotoxicity, and metal release in patients with fixed orthodontic appliances: A longitudinal in-vivo study. American Journal of Orthodontics Dentofacial Orthopedics 140(3), 298-308 (2011)

4. Jamal, A, Alsanea, Hassan, Al, Shehri: Evaluation of nanomechanical properties, surface roughness, and color stability of esthetic nickel-titanium orthodontic archwires. Journal of International Society of Preventive Community Dentistry (2019)

5. Fahed, Tannous, , , Martin, Steiner, , , Ramez, Shahin, , , and, M.: Retentive forces and fatigue resistance of thermoplastic resin clasps. Dental Materials (2012)

6. Shirakawa, Nobukazu, Iwata, Toshio, Miyake, Shinjiro, Otuka, Takero, Koizumi, and, S.: Mechanical properties of orthodontic wires covered with a polyether ether ketone tube. Angle Orthodontist (2018)

7. Doshi, U.H., Bhad-Patil, W.A.: Static frictional force and surface roughness of various bracket and wire combinations. American Journal of Orthodontics Dentofacial Orthopedics 139(1), 74-79 (2011)

8. [, Lanyue, Chen, Xudong, Yan, Lili, Tan, Bowen, Zheng, and, F.: In vitro and in vivo characterization of novel calcium phosphate and magnesium (cap-mg) bilayer coated titanium for implantation. Surface Coatings Technology (2019)

9. Muhammad, Qadir, Yuncang, Cuie, Wen: lon-substituted calcium phosphate coatings by physical vapor deposition magnetron sputtering for biomedical applications: A review. Acta biomaterialia (2019)

10. Swann, S: Magnetron sputtering. Physics in Technology 19(2), 67 (1988)

11. Kao, W.H., Su, Y.L., Horng, J.H., Hsieh, Y.T.: Improved tribological properties, electrochemical resistance and biocompatibility of aisi $316 \mathrm{I}$ stainless steel through duplex plasma nitriding and tin coating treatment. Journal of Biomaterials Applications 32(1), 885328217712109 (2017)

12. DÄntò, V., Rongo, R., Ametrano, G., Spagnuolo, G., Manzo, P., Martina, R., Paduano, S., Valletta, R.: Evaluation of surface roughness of orthodontic wires by means of atomic force microscopy. Angle Orthodontist 82(5), 922-8 (2012) 
13. Abdullah, A.O., Muhammed, F., Pollington, S., Liu, Y.: Comparative in vitro evaluation between zirconia and veneer ceramic materials using different techniques. Journal of Materials Engineering and Performance 28(11), 6656-6668 (2019)

14. Zhang, H., Guo, S., Wang, D., Zhou, T., Wang, L., Ma, J.: Effects of nanostructured, diamondlike, carbon coating and nitrocarburizing on the frictional properties and biocompatibility of orthodontic stainless steel wires. Angle Orthodontist, 782 (2016)

15. Joanna, M., Katarzyna, N.L., ?ysik Dawid, Gra?Yna, T., Jan, D., Robert, B.: The role of oral cavity biofilm on metallic biomaterial surface destruction-corrosion and friction aspects. International Journal of Molecular ences 19(3), 743 (2018)

16. Meyer, R.D., Meyer, J., Taloumis, L.J.: Intraoral galvanic corrosion: Literature review and case report. Journal of Prosthetic Dentistry 69(2), 141 (1993)

17. Song, F., Koo, H., Ren, D.: Effects of material properties on bacterial adhesion and biofilm formation. Journal of Dental Research 94(8), 1027-1034 (2015)

18. Kati?, V., Urkovi, H.O., Semenski, D., Bar?I?, G., Maru?!?, K., ?palj, S.: Influence of surface layer on mechanical and corrosion properties of nickel-titanium orthodontic wires. The Angle Orthodontist 84(6), 1041-8 (2014)

19. Kim, H., Johnson, J.W.: Corrosion of stainless steel, nickel-titanium, coated nickel-titanium, and titanium orthodontic wires. Angle Orthodontist 69(1), 39-44 (1999)

20. Kusy, R.P., Whitley, J.Q.: Friction between different wire-bracket configurations and materials. Seminars in Orthodontics 3(3), 166 (1997)

21. Marijana, Mlinaric, R., Sven, Karlovic, Zlatko, Ciganj, Pop, D., Acev, Andrej, and, P.: Oral antiseptics and nickel-titanium alloys: mechanical and chemical effects of interaction. Odontology (2018)

22. De, A.C.G., Bortolazzo, C.A., Cherubini, V.G., Milton, S.J., Alberto, T.C., Scudeler, V.S.A.: Deflection and flexural strength effects on the roughness of aesthetic-coated orthodontic wires. Braz Dent J 28(1), 40-45 (2017)

23. Anuradha, P., Varma, N.K.S., Balakrishnan, A.: Reliability performance of titanium sputter coated ni-ti arch wires: Mechanical performance and nickel release evaluation. Bio-Medical Materials and Engineering (2015)

24. Alavi, S., Hosseini, N.: Load-deflection and surface properties of coated and conventional superelastic orthodontic archwires in conventional and metal-insert ceramic brackets. Dental Research Journal 9(2), 133 (2012)

25. Pan, X., Li, Y., Abdullah, A.O., Wang, W., Qi, M., Liu, Y.: Micro/nano-hierarchical structured tio2 coating on titanium by micro-arc oxidation enhances osteoblast adhesion and differentiation. Royal Society Open ence 6(4) (2019) 


\section{Figures}

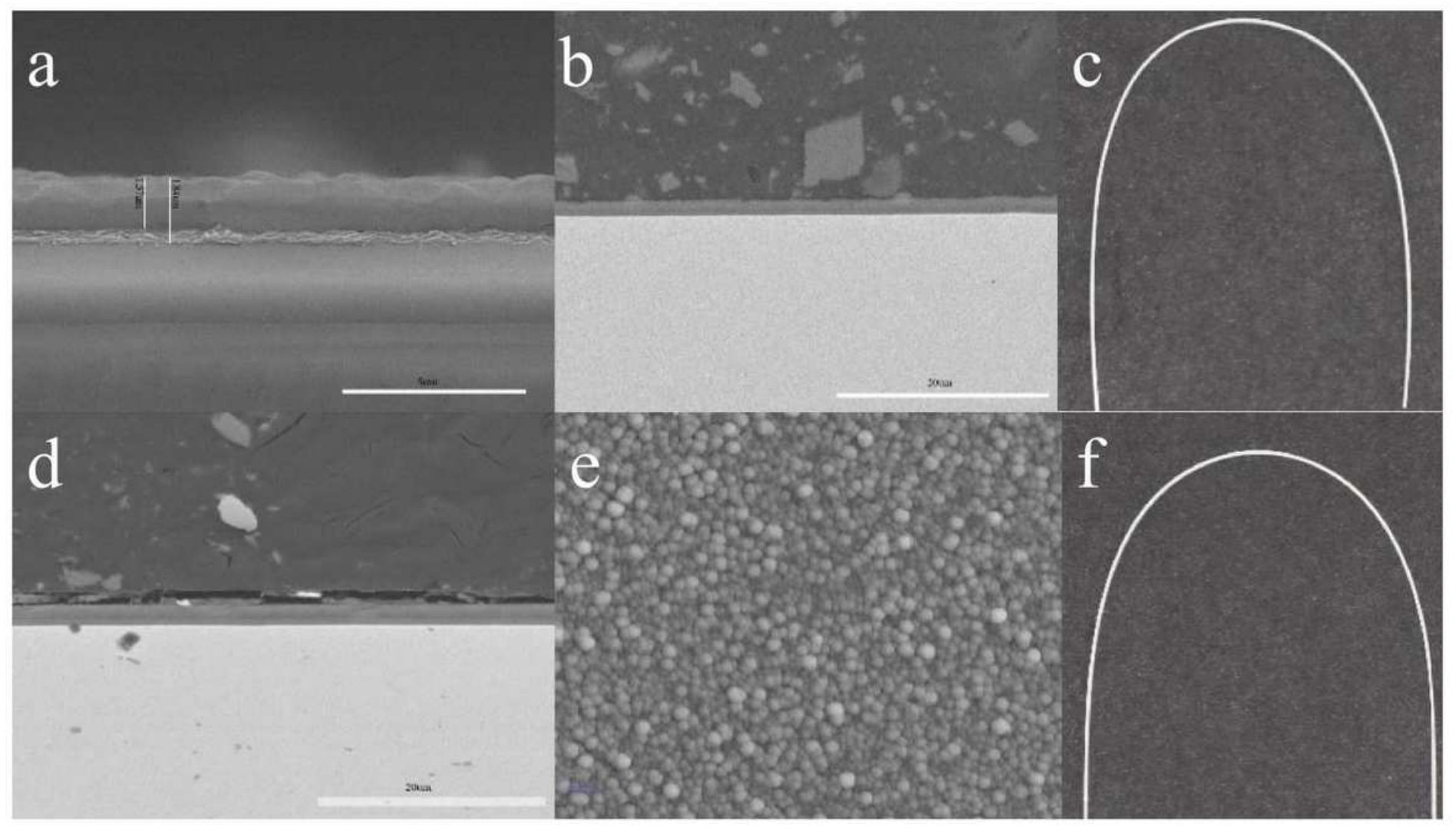

\section{Figure 1}

SEM observation and archwire morphology of Al - SiO2 coated layer.(a: coating thickness; b: stainless steel section; c: nickel-titanium section; d: coating surface; e: the morphology of NiTi archwire; f: the morphology of stainless steel archwire)

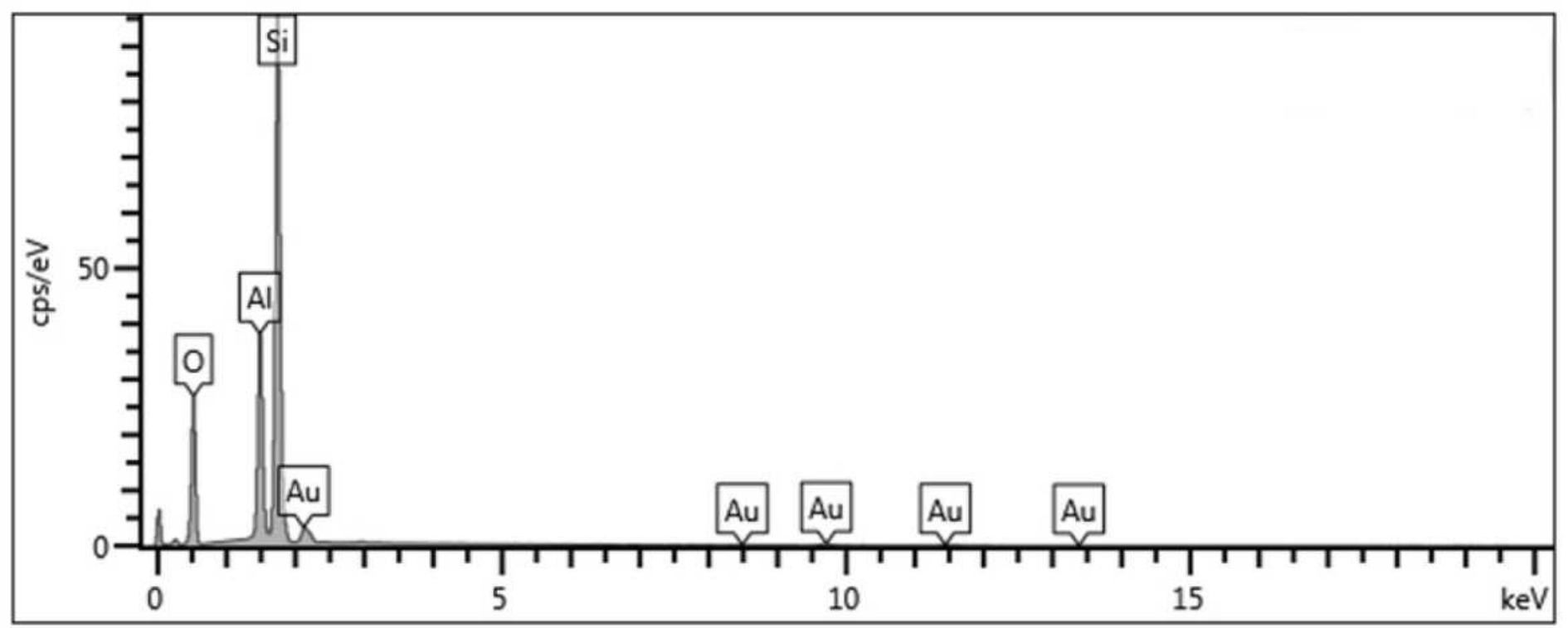

Figure 2 


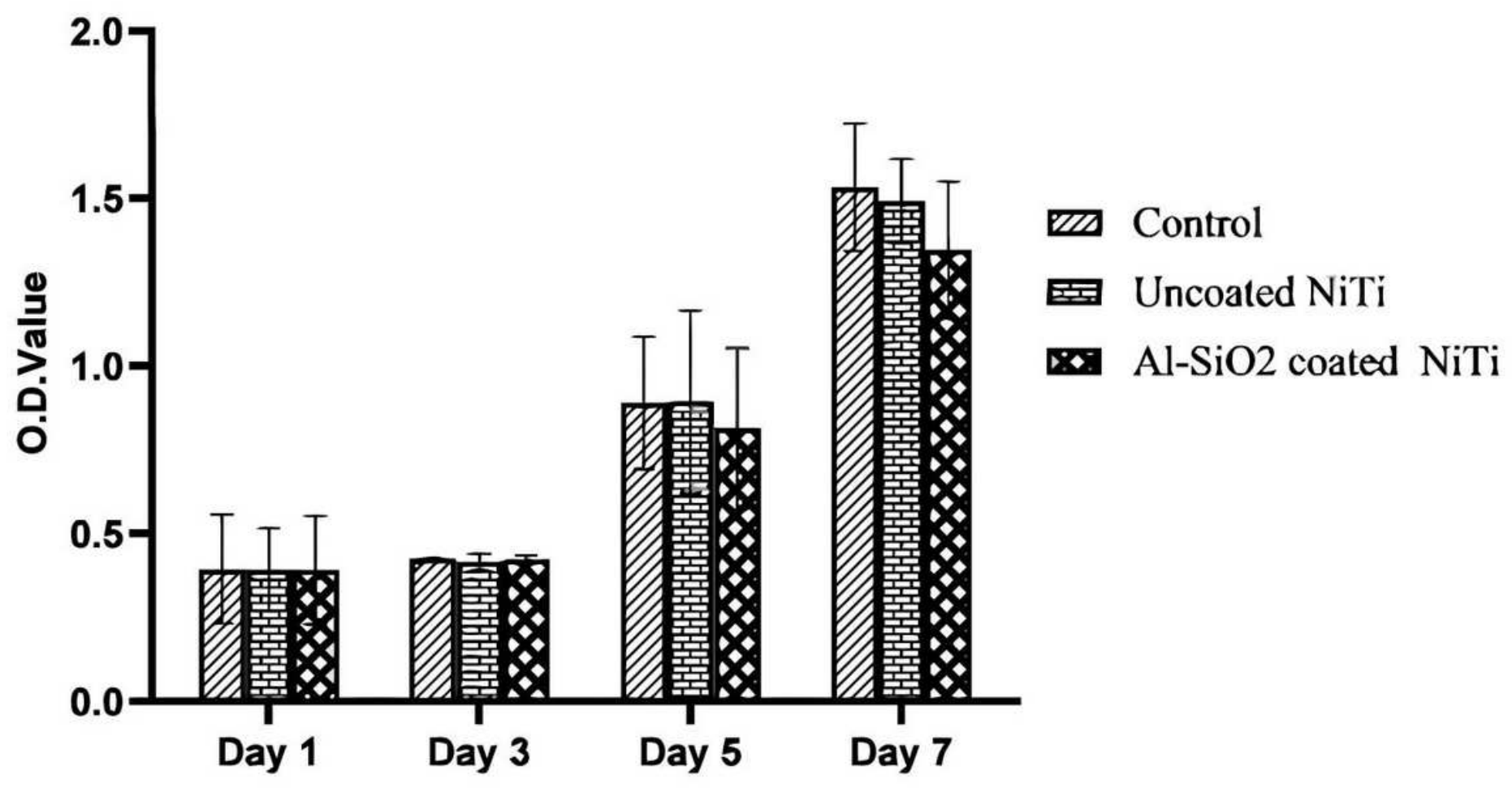

Figure 3

Optical density (OD) values at different time points in the NiTi group

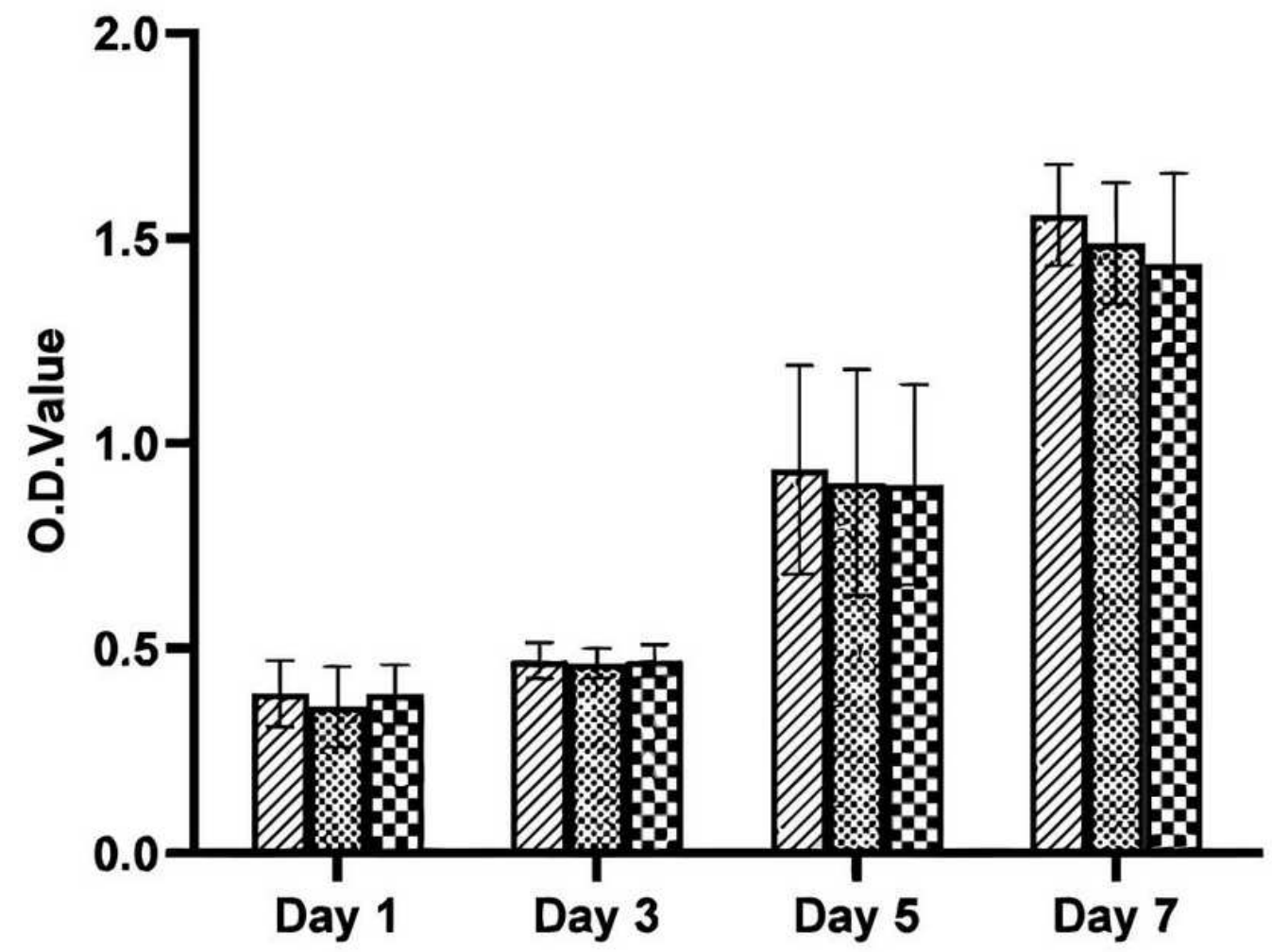

WD Control

Uncoated SS

HAl-Sion coated SS

Figure 4 
Optical density (OD) values of mouse broblasts at different time points in the stainless steel group

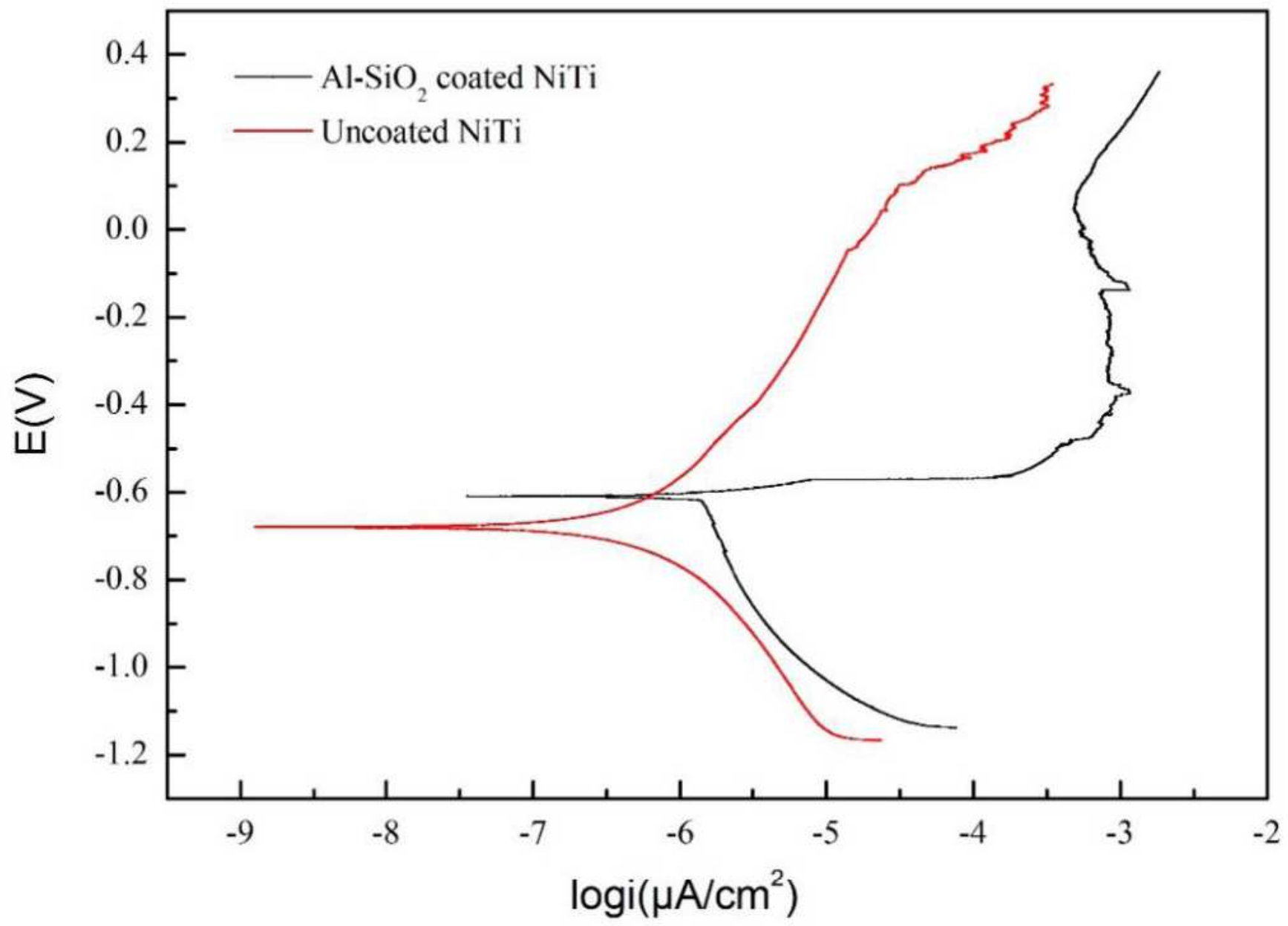

Figure 5

Dynamic polarization curve of NiTi group 


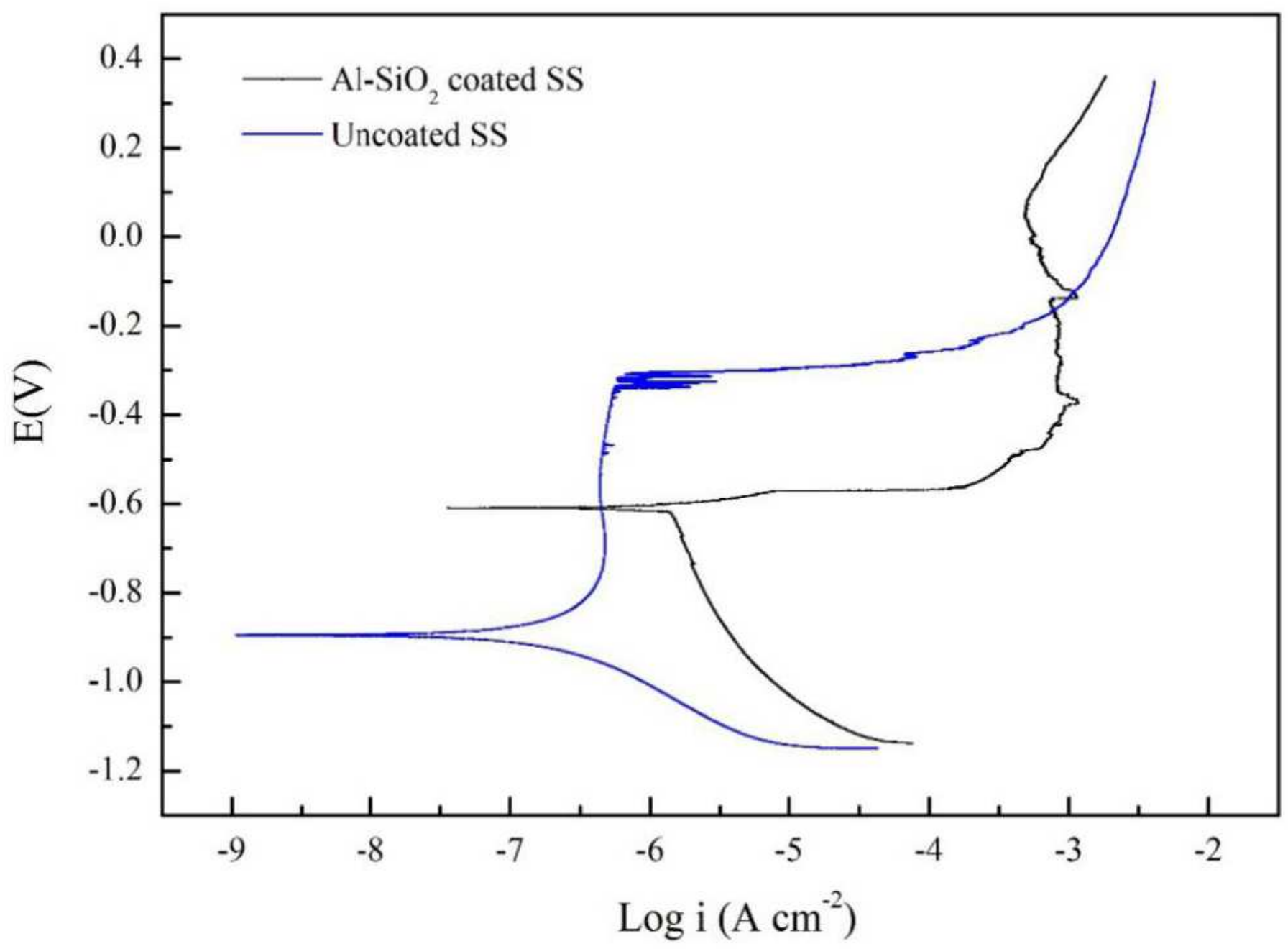

Figure 6

Dynamic polarization curve of stainless steel group 


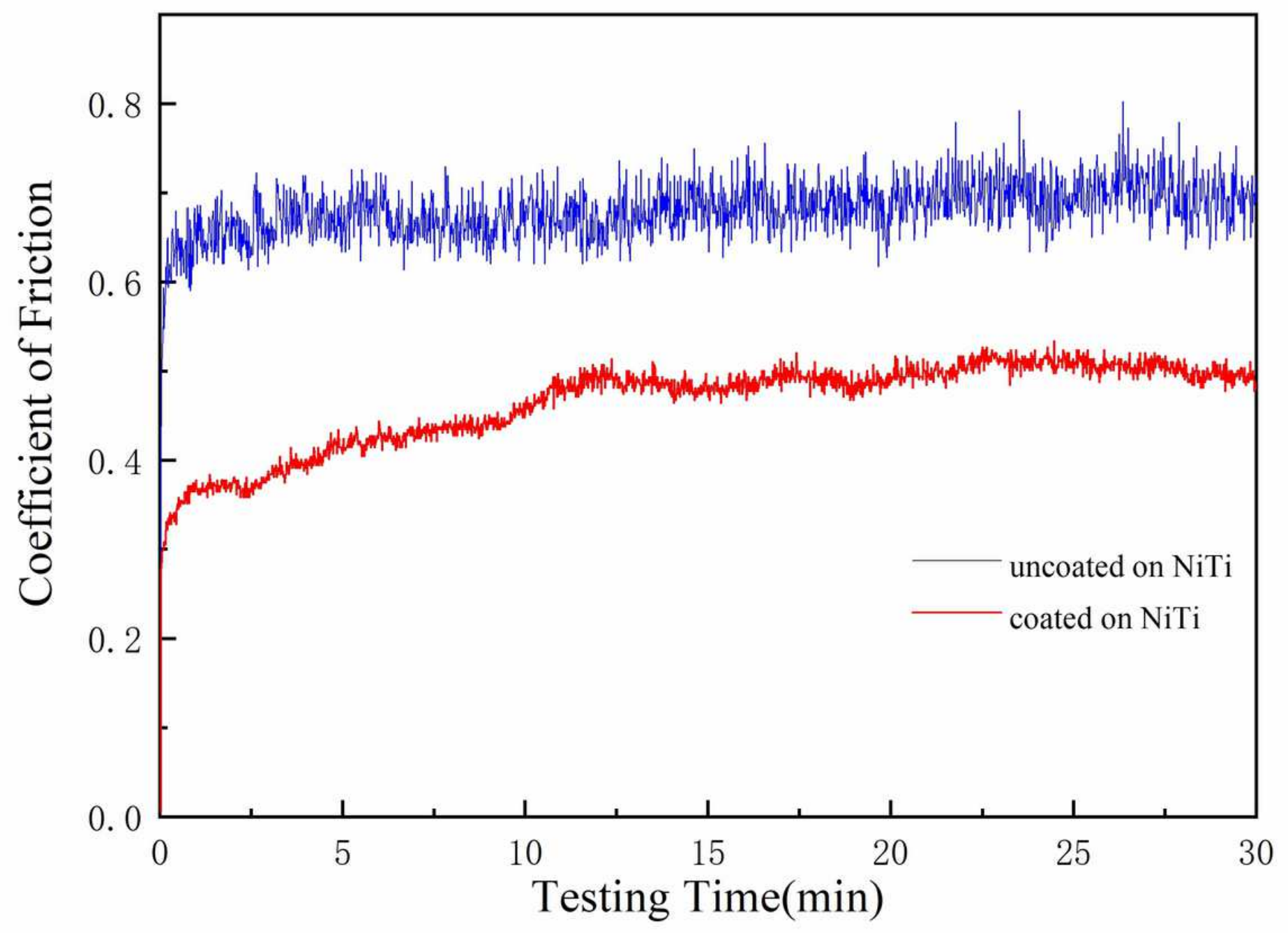

Figure 7

Friction coeffient curve of NiTi group 


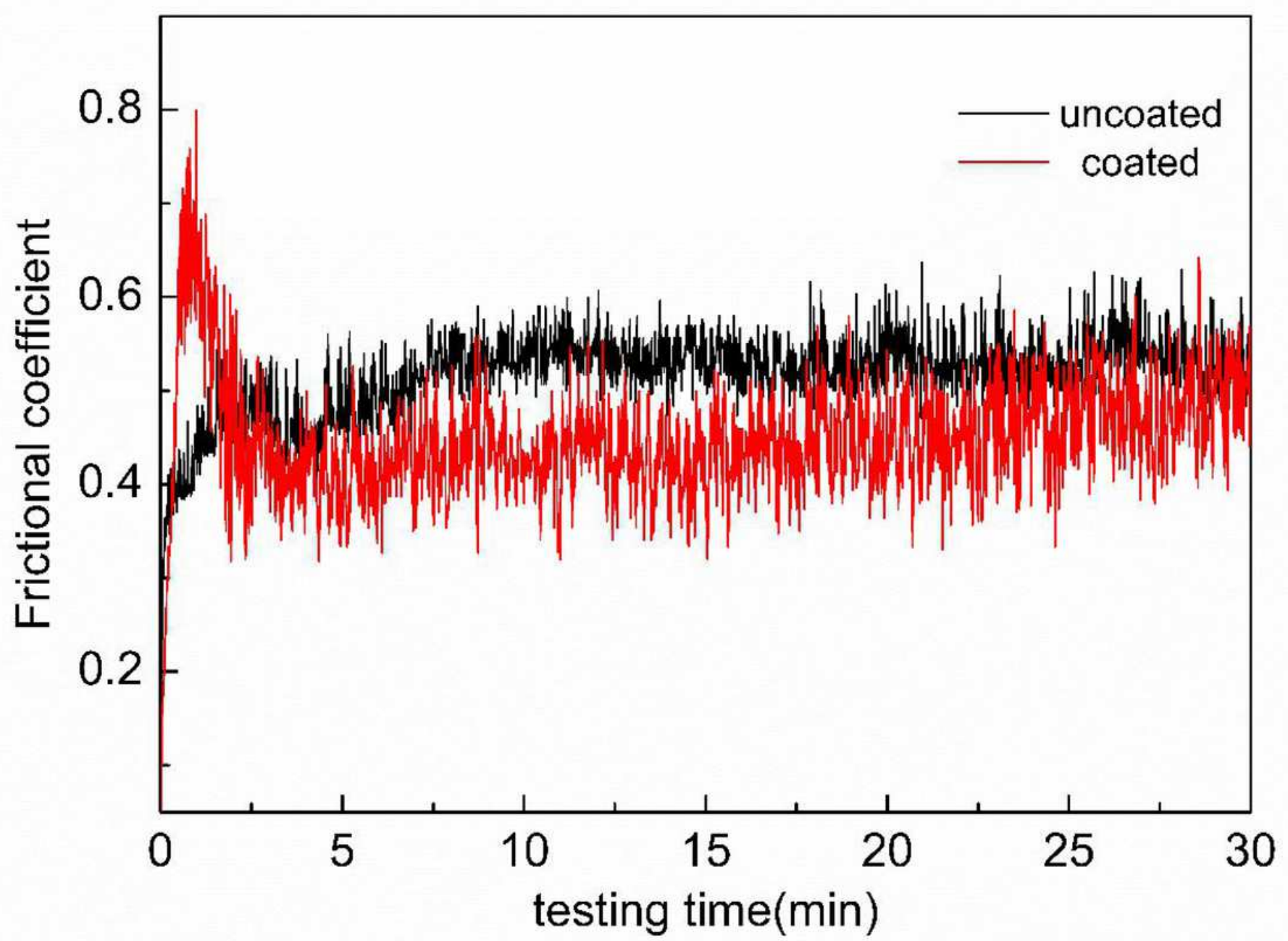

Figure 8

Friction coefficient curve of stainless steel group

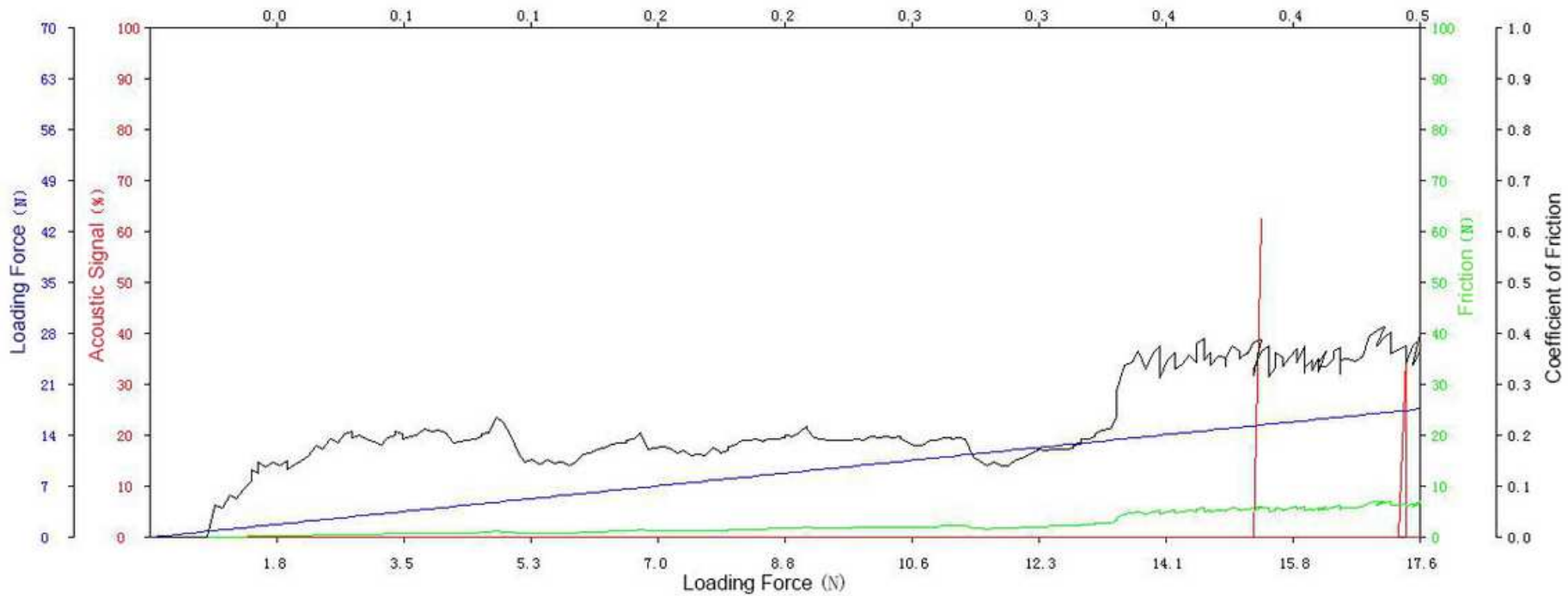


Figure 9

The scratch test shows coated NiTi specimen

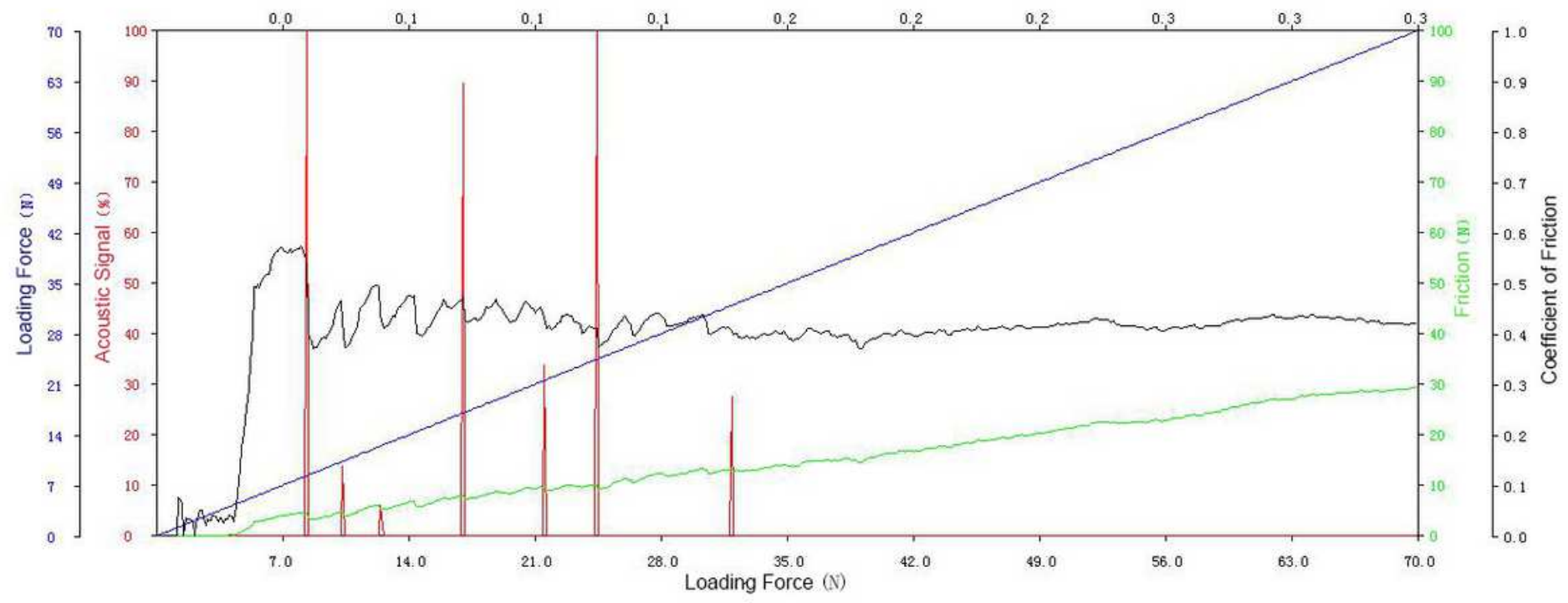

Figure 10

The scratch test shows coated stainless steel specimen 